Revista Eletrônica do Mestrado em Educação Ambienta1

Programa de Pós-Graduação em Educação Ambiental

\title{
Educação Ambiental, estudo do meio e internalização do conhecimento
}

\author{
Rodrigo José de Góis Queiroz ${ }^{1}$ \\ Universidade Federal do Ceará \\ ORCID: http://orcid.org/0000-0002-7433-4615
}

Resumo: Neste artigo buscamos pensar a educação ambiental como um processo de ensino e aprendizagem voltado para conscientização social perante a crise ambiental. Tendo como pano de fundo uma crítica da modernidade no qual reconhecemos a mesma como momento histórico de aprofundamento do crescimento econômico e transformação da natureza em valor de troca, propomos uma educação ambiental crítica na perspectiva da construção do conhecimento. Apresentamos um levantamento teórico sobre o processo de internalização do conhecimento, culminando na metodologia pedagógica do estudo do meio. Assim, traçamos uma proposta socioconstrutivista que visa contribuir com a apropriação do conhecimento por parte dos estudantes, no caminho da formação humana de sujeitos ecológicos em luta pela cidadania e justiça ambiental.

Palavras-chave: Educação ambiental; Socioconstrutivismo; Sujeito ecológico.

\section{Educación Ambiental, estudio del médio y internalización del conocimiento}

Resumen: En este artículo tratamos de pensar en la educación ambiental como un proceso de enseñanza y aprendizaje orientado a la conciencia social ante la crisis ambiental. Con el trasfondo de una crítica de la modernidad en la que la reconocemos como momento histórico de profundización del crecimiento económico y transformación de la naturaleza en valor de cambio, proponemos una educación ambiental crítica en la perspectiva de la construcción del conocimiento. Presentamos un estudio teórico sobre el proceso de internalización del conocimiento, culminando en la metodología pedagógica del estudio del médio. Así, establecemos una propuesta socioconstructivista que desea contribuir con lá apropiación del conocimiento por parte de los estudiantes, en el caminho de la formación humana de sujetos ecológicos en lucha por la ciudadania y justicia ambiental.

Palabras clave: Educación ambiental; Socioconstructivismo; Sujeto ecológico.

\section{Environmental Education, milieu analysis and knowledge internalization}

\footnotetext{
${ }^{1}$ Doutor em Geografia pela Universidade Federal do Ceará. Licenciado em Geografia pela Universidade Estadual do Ceará. E-mail: joserodrigois@ yahoo.com.br
} 
Abstract: In this article we seek to think of environmental education as a teaching-learning process aimed at social awareness in face of the environmental crisis. Against the background of a critique of modernity in which we recognize it as a historical moment for deepening economic growth and transforming nature into exchange value, we propose a critical environmental education in the perspective of knowledge construction. We present a theoretical survey about the knowledge internalization process and the pedagogical methodology of milieu analysis. Thus, we present a socio constructivist proposal that aims to contribute to the appropriation of knowledge by students, for the formation of ecological persons in the struggle for citizenship and environmental justice.

Keywords: Environmental Education; Social constructivism; Ecological person.

\section{Introdução}

Neste artigo buscamos como eixo central uma discussão sobre a crise ambiental contemporânea e a necessidade de uma educação ambiental crítica. Apresentamos autores que destacam as possibilidades de um processo de conscientização ambiental através de uma educação renovada, pautada na superação do verbalismo no contexto de ensino e aprendizagem. Assim, se faz de fundamental importância uma articulação interdisciplinar entre as diversas disciplinas da educação formal, no caminho da reformulação do currículo da escola, buscando valorizar as experiências e conhecimentos prévios dos estudantes em articulação com as teorias e conhecimentos científicos, sob a mediação pedagógica dos docentes.

Em termos de metodologia, trabalhamos com uma revisão bibliográfica sobre as questões relativas à crise ambiental, bem como da necessidade de uma educação ambiental com base na proposta pedagógica socioconstrutivista. A questão do processo de internalização do conhecimento através de práticas pedagógicas ativas é um tema basilar em nossa discussão, tendo em vista que propomos uma educação ambiental crítica no caminho da formação de sujeitos ecológicos na luta pela cidadania e justiça ambiental. Para tanto, propomos o estudo do meio como uma metodologia de ensino e pesquisa na educação básica como forma de aproximação dos estudantes com a problemática ambiental no bairro da escola. Tal proposta pode ser trabalhada pelos professores no ensino fundamental II e ensino médio ${ }^{2}$.

Com base em nossa experiência de docência em cursos de formação de professores, destacamos a importância da materialização do conhecimento após as atividades de pesquisa, em que apontamos a prática pedagógica do teatro de fantoches como uma forma de retorno à comunidade com os resultados do estudo do meio. Ao longo do artigo, explicitamos o passo a passo para a organização do estudo do meio como uma

\footnotetext{
${ }^{2}$ Vigotsky (2014) alerta sobre os períodos de desenvolvimento cognitivo na criança e adolescente, ressaltando a importância da imaginação criativa objetiva que vem das suas experiências vividas depois dos 7 anos de idade.
} 
atividade que procura mobilizar toda a comunidade escolar, bem como o processo de construção dos fantoches de forma ecológica através de material reciclado. Essa proposta de educação ambiental mobiliza o estudante de forma ativa no caminho de uma aprendizagem significativa.

\section{Educação Ambiental no contexto de crise}

A educação ambiental crítica surge como uma proposta pedagógica com ênfase na busca pelo entendimento das contradições da relação entre sociedade e natureza no mundo moderno. Através de uma análise interdisciplinar, pautada na contribuição teórica de diversos campos do conhecimento, a mesma busca desvendar a complexidade da problemática ambiental. Como se sabe, o século XX trouxe à tona a problemática da crise ambiental, evidenciando que os recursos naturais não conseguem responder ao ritmo econômico de transformação da natureza visando o lucro. Assim, de acordo com Carvalho (2011, p. 116): “o paradigma moderno entrou em crise justamente por não conseguir responder adequadamente aos novos problemas teóricos e práticos que atravessam a vida contemporânea, entre os quais os ambientais".

Nessa perspectiva, fica claro que a ciência moderna ao separar epistemologicamente a natureza da sociedade, adotou um racionalismo econômico que legitimou a dominação da natureza. Contudo, para Moraes (2005), a questão central não seria a unidade entre sociedade e natureza, mas como separaram algo que é unido. Para ele: “a ligação natural com a natureza é quebrada através das regras estabelecidas no convívio social". (MORAES, 2005, p. 75). De acordo com o autor, assim, a natureza aparece como condição da produção econômica, em que: “o homo tecnológicus possui um relacionamento mais intenso com os recursos naturais do que seus ancestrais, ao mesmo tempo em que encontra-se mais liberado dos limites impostos pela natureza". (MORAES, 2005, p.102).

Por outro lado, de acordo com Moraes (2005), uma visão romântica da natureza também não contribui no entendimento crítico da relação sociedade e natureza. Para ele: "Do ponto de vista da questão ambiental, o romantismo se manifesta, por exemplo, no preservacionismo radical que, no limite, pode veicular perspectivas anti-humanistas ao colocar a natureza como um valor maior que o homem" (MORAES, 2005, p. 55). Para o autor, o resgate da perspectiva da teoria crítica da "Escola de Frankfurt" apresenta uma reflexão interessante, pois lança questionamentos em torno do tecnicismo capitalista e sua 
razão instrumental, propondo uma razão crítica que valorize os saberes e a memória das classes oprimidas. Por sua vez, pode-se dizer que o tecnicismo na questão ambiental traz uma aura de verdade e neutralidade, mas está associado ao domínio do econômico.

Dessa forma, fica claro que sob o capitalismo a natureza aparece como recurso econômico, uma condição para as atividades produtivas, fornecendo a matéria prima da produção de mercadorias. No interior dessa dinâmica, ao longo do século XX, observamos o processo alucinado de urbanização e expansão da produção capitalista, que tem como marco o período histórico após a segunda guerra mundial. A generalização do processo de urbanização alerta sobre a problemática do meio ambiente na cidade, especialmente com a expansão da poluição, que vem ganhando força na esteira da sociedade pautada pelo consumo.

Para Rodrigues (1998), o conceito de meio ambiente urbano alerta para esta problemática. Segundo a autora, os resíduos apresentam-se em estado sólido, semissólido, líquido e gasoso. Com relação aos resíduos sólidos e semissólidos, é perceptível a grande problemática que estes trazem às cidades em relação a capacidade de armazená-los, provocando entupimento de bueiros que aceleram e induzem a problemática das enchentes, principalmente nos bairros pobres. Sobre a forma de líquidos concentram-se nos rios, córregos, lençóis freáticos e oceanos, provocando a poluição hídrica, causando inúmeros impactos no consumo de água. No que diz respeito aos resíduos gasosos, a autora destaca as indústrias como grandes poluidoras da atmosfera, e afirma que dependendo das massas de ar, podem causar inúmeras doenças.

Como argumenta o historiador Hobsbawm (2015), o período após a segunda guerra mundial foi marcado pela "Era de Ouro" do capitalismo, que proporcionou índices de acumulação de capital nunca existentes através de uma expansão nunca vista do consumo de mercadorias, que encontrou um aliado na ideologia da publicidade e da venda do modo de vida "americano". Por outro lado, certamente os últimos anos apresentam um grande pico de crise econômica, em que devemos compreendê-los como um processo que vem se desenrolando desde 1973 em um continuum depressivo (CHESNAIS, 1996).

Em meio a esse processo, os capitalistas vêm tentando incessantemente recompor suas margens de lucro, adotando estratégias de acumulação flexibilizadas bem como procurando novos setores de acumulação, no que conhecemos como reestruturação produtiva. Uma das estratégias mais conhecidas diz respeito a diminuição da vida útil das mercadorias, reconhecida como obsolescência programada, que visa ampliar a produção e rotação do consumo. Ademais, também temos o surgimento do agronegócio como uma 
reestruturação das formas de acumulação capitalista no campo, promovendo inúmeros impactos ambientais de erosão dos solos e poluição dos corpos hídricos, bem como danos à saúde com a produção alimentar de transgênicos.

Nesse contexto, surgem as propostas de Educação ambiental como parte do movimento ecológico nos anos 1970, identificando os processos capitalistas de dominação da natureza e a crise ambiental contemporânea. Para Carvalho (2012), a educação ambiental busca uma prática de conscientização acerca da finitude dos recursos naturais no contexto de uso capitalista, envolvendo os cidadãos em ações sociais críticas. De acordo com a autora, no plano teórico, a Educação ambiental propõe uma visão socioambiental que não nega a base "natural" da natureza, mas chama atenção para os limites de sua apreensão física e biológica. Para a autora: "trata-se de reconhecer que, para apreender a problemática ambiental, é necessário uma visão complexa de meio ambiente, em que a natureza integra uma rede de relações". (CARVALHO, 2012, p. 38).

Nessa perspectiva, de acordo com Carvalho, (2011, p. 29): "Educação ambiental vem sendo valorizada como uma ação educativa que deveria estar presente, de forma transversal e interdisciplinar, articulando o conjunto de saberes, formação de atitudes e sensibilidades ambientais". Assim, através de uma atitude interdisciplinar, vamos propor pensar uma proposta de educação ambiental no campo das perspectivas socioconstrutivistas $^{3}$, apresentando atividades práticas, que resultam em novas formas de construção do conhecimento ambiental, buscando articular uma luta pela cidadania, saindo da sala da aula para construir o conhecimento contextualizado com a realidade vivida.

No que diz respeito a construção do conhecimento ambiental, podemos lançar mão de propostas de interdisciplinaridade para pensar uma educação ambiental crítica na busca da formação de sujeitos ecológicos. Nesse caso, as atividades práticas se voltarão para uma articulação com os movimentos sociais, buscando construir um conhecimento que vem da prática. Nessa perspectiva, acreditamos que as atividades podem ser organizadas a depender das demandas, interesses e necessidades, através de atividades de campo, estudos do meio, entrevistas, rodas de conversa, até mesmo uma autorreflexão sobre o espaço vivido pelo próprio estudante, levando em conta a experiência do indivíduo e dos coletivos sociais em suas relações com o ambiente.

\footnotetext{
${ }^{3}$ Bem entendido, a perspectiva socioconstrutivista tem sua base na filosofia da educação desenvolvida por Vigotsky, especialmente no que diz respeito a aprendizagem significativa. Para Vigotsky, a educação passa pela inter-relação entre os aspectos cotidianos e científicos do conhecimento, pois a aprendizagem somente é significativa a partir da necessária apropriação do objeto do conhecimento pelos educandos.
} 
Assim, de acordo com Carvalho (2012), são possíveis inúmeras práticas pedagógicas com a perspectiva da educação ambiental, desde que adotemos uma perspectiva que analise a sociobiodiversidade, como uma tentativa de apreender as interações complexas entre sociedade e natureza. Para a autora, no tocante a Educação ambiental, se faz de suma importância a dimensão interdisciplinar na construção do conhecimento, superando o conhecimento disciplinar despedaçado, compartimentalizado e fragmentado, que reduz a complexidade do real, "impossibilitando uma compreensão diversa e multifacetada das inter-relações que constituem o mundo da vida" (CARVALHO, 2012, p. 120). A autora deixa claro:

A crise ambiental, de certa forma, alimenta esses questionamentos epistemológicos e desacomoda os modos já aprendidos de pensar da racionalidade moderna, ao expor a insuficiência dos saberes disciplinares e reivindicar novas aproximações para que se compreenda a complexidade das inter-relações na base dos problemas ecológicos (CARVALHO, 2012, p. 123).

Na defesa da importância da interdisciplinaridade como forma de construção do conhecimento ambiental, a autora relata que no mundo vivido os aspectos tomados de forma isolada pelas diversas disciplinas estão permanentemente relacionados. Nesse caminho, cada área do conhecimento, de forma separada, perde a visão de conjunto, traduzindo as contradições da realidade de uma forma unidimensional. Entretanto, para Carvalho (2012, p. 132), “Os problemas ambientais ultrapassam a especialização do saber", se expressando em problemáticas totalizantes como o aquecimento global; os desequilíbrios climáticos; a crise urbana; a poluição de rios e mananciais que tem diminuído a oferta de água potável; os problemas de saúde acarretados por alimentos transgênicos, dentre outros.

Com isso, através de uma Educação ambiental crítica, podemos construir em conjunto com os estudantes a noção de humanização da técnica, levando em consideração a necessidade da preservação da natureza através da crítica dos "modelos de desenvolvimento" que negam a perspectivas sociais. Uma possibilidade muito rica de estudo interdisciplinar no campo da Educação ambiental são os "estudos do meio". De acordo com Carvalho (2012), essa proposta busca compreender a interação da paisagem humana com o meio físico, através de práticas pedagógicas que valorizam a educação ao ar livre, como o trabalho de campo e a experiência direta com o entorno da escola. Desta feita, na sequência buscamos aprofundar o entendimento sobre a proposta pedagógica 
socioconstrutivista, culminando com uma apresentação da proposta de Educação ambiental crítica através dos estudos do meio.

\section{Pedagogia socioconstrutivista e internalização do conhecimento}

$\mathrm{Na}$ proposta pedagógica socioconstrutivista, as funções mentais superiores do estudante desenvolvem-se na relação entre suas experiências socioculturais e os conhecimentos científicos produzidos ao longo da história da humanidade. Para Vigotsky (2001), a relação ensino-aprendizagem apoiada em conceitos desconectados da experiência vivida dos estudantes se torna estéreo, pois ocorre uma memorização da palavra e não um aprendizado do conteúdo. Por outro lado, em seus estudos, ele observa que na relação espontânea com as problemáticas vividas o estudante atinge um certo nível de desenvolvimento cognitivo. Contudo, no contexto de ensino e aprendizagem propiciada por uma educação crítica, o estudante apresenta um nível de desenvolvimento cognitivo superior.

Como endossa Castorina (1998, p. 162), na proposta de Vigotsky, o desenvolvimento cognitivo ocorre pela relação entre elementos do meio sociocultural vivido pelo estudante e sistemas de linguagens e signos culturais, em que "os docentes têm uma atividade tutelar, de sustentação do acesso dos estudantes aos saberes mais avançados". A tarefa do professor desenvolve-se através de ações didático-pedagógicas necessárias à construção conjunta do conhecimento. Para o autor, especialmente na infância e adolescência, a contribuição do professor torna-se decisiva, pois os estudantes necessitam de sua colaboração para realizar as ações necessárias à aprendizagem.

Assim, o processo de construção do conhecimento passa pela superação da forma de ensino e aprendizagem pautada na memorização. $\mathrm{Na}$ proposta pedagógica socioconstrutivista, essa superação se dá pelo processo de internalização do conhecimento, que é a reformulação das teorias pelo choque necessário entre os conhecimentos cotidianos e científicos, culminando em uma reconstrução interna do conhecimento e a consequente apropriação do mesmo. De acordo com Castorina (1998), a internalização do conhecimento se dá na interação social ativa entre os diferentes sujeitos do conhecimento, qual seja, estudantes e professores.

Para esse autor, a internalização, ou aprendizagem, se inicia no acesso ao conhecimento produzido historicamente pela humanidade, que através da mediação do professor com a contribuição dos instrumentos culturais passa para o plano interno da 
imaginação do estudante. Nesse processo ocorre uma reconstrução do conhecimento pelo próprio estudante com base na sua realidade vivida, em que o professor fornece instrumentos para que ele faça uma análise própria. Assim, a internalização acontece após a construção do conhecimento de forma ativa, superando as teorias prontas desconectadas da realidade, para uma perspectiva que faça sentido para a vida, e, assim, forneça elementos para o entendimento da produção social da realidade.

Na proposta de Vigotsky (2001), ocorre a valorização dos conhecimentos adquiridos de forma espontânea pelos estudantes, pois estes apresentam sinais da realidade vivida. Assim, no processo educativo, é de suma importância resgatar esses conhecimentos, pois não há nada pior para os estudantes do que a imposição de um tema que ele pouco pensou. Dessa forma, se faz necessário desenvolver o interesse do estudante na construção do conhecimento e isso passa pelo trato educativo das suas experiências e das representações construídas sobre elas. Na pedagogia escolástica, por outro lado, o processo educativo era orientado pelo verbalismo, no sentido de incutir artificialmente conceitos e teorias que lhes eram completamente alheios.

Para Vigotsky (2001), uma educação que faça sentido para os estudantes apresenta maior sucesso, pois busca articular temas vividos que ele compreende, que o emocione, estimulando-o na busca do entendimento dos processos. Essa forma de ensino e aprendizagem passa pela problematização das experiências vividas, compreendendo que os desafios cotidianos contribuem com a mobilização individual no interior do processo de construção do conhecimento. Nesse caminho, se faz de fundamental importância ressaltar a relação dialética entre cotidiano e totalidade na produção do conhecimento.

Para Kosik (1976), o princípio metodológico da investigação dialética da realidade social é o ponto de vista da totalidade concreta, que antes de tudo, "significa que cada fenômeno pode ser compreendido como momento do todo" (KOSIK, 1976, p. 49). Em sua argumentação, o autor afirma que a dialética não pode compreender a totalidade como um todo já feito que determine as partes, pois seria uma falsa totalização, se manifestando no princípio abstrato que despreza a riqueza do real. Para o autor, vale destacar, no movimento em espiral da realidade, o presente sempre é mais rico que o passado, sendo o aspecto cotidiano elemento rico em novidades.

Nesse sentido, o autor alerta para o fato de que o aspecto cotidiano traz o novo como possibilidade, ressaltando a importância da pesquisa enquanto elemento fundamental para desconstrução de hipóteses cristalizadas. Como afirma Marx (2007, p. 533), em sua segunda tese Ad Feuerbach: "a disputa acerca da realidade ou não realidade de um 
pensamento que se isola da prática é uma questão puramente escolástica”. Ademais, retomando o entendimento da práxis em sua articulação entre teoria e prática, observamos que a reflexão teórica vem da prática e volta para ela, reiterando a necessidade da interação entre conhecimento teórico e a vivência cotidiana.

Por outro lado, Kosik (1976) alerta que a dialética diferencia a "representação" da "coisa em si", na medida em que este último não se manifesta imediatamente ao homem, sendo necessário um esforço de pesquisa para se chegar à "coisa em si". Aqui, pensando a questão educacional, salientamos a importância da relação de interação entre professores e estudantes no tocante aos conhecimentos cotidianos e científicos, no caminho da superação de uma educação verbalista, trazendo a importância de práticas pedagógicas ativas na construção do conhecimento.

Nesse caminho, em outra obra, Vigotsky (2014) ressalta que o conhecimento científico sempre é um produto social da criatividade humana que relaciona o ambiente vivido pelo pesquisador com o conhecimento produzido historicamente pela humanidade, no qual o mesmo parte dos níveis alcançados anteriormente pela ciência para alçar novos voos. Ele afirma que a obra criativa, quer seja científica, técnica ou artística, se desenvolve tendo por base a precedente. Partindo desse pressuposto, o autor argumenta sobre a importância da difusão da educação e do conhecimento entre as diferentes classes sociais na busca de expandir as possibilidades de construção do conhecimento, afirmando:

É exatamente isso que explica a distribuição desproporcional dos inovadores e cientistas entre diferentes classes sociais. As classes privilegiadas deram origem a uma percentagem consideravelmente maior de criadores na ciência, na técnica e na arte, porque tinham em suas mãos todas as condições necessárias para a criação. (VIGOTSKY, 2014, p. 32).

Por conseguinte, a expansão da educação escolar como forma de socialização do conhecimento historicamente produzido pela humanidade, associada com as experiências vividas dos estudantes, tem o potencial de construção do conhecimento e de generalização da criatividade como qualidade humana. Para Vigotsky (2014), uma educação voltada para criatividade tem como característica a busca pela transformação ativa da vida social, diferente de uma educação verbalista que encaminha os sujeitos para contemplação e apatia perante a realidade social. Assim, a perspectiva socioconstrutivista da educação aponta para busca do uso consciente do conhecimento pelos estudantes através da internalização e reconstrução do mesmo com base na realidade vivida, no caminho da formação de sujeitos ativos na produção social da realidade. 
Para Vigotsky (2001), assim, surge o conceito de Zona de Desenvolvimento Imediato, que reitera o papel do professor na relação ensino-aprendizagem. Ele argumenta que os estudantes em sua relação espontânea com a realidade vivida apresentam um certo nível de desenvolvimento cognitivo, reconhecido como imediato. Com a intervenção do professor no contexto escolar, como mediador do conhecimento científico, o nível de desenvolvimento cognitivo se torna superior. Ele ressalta que a perspectiva socioconstrutivista aponta para autonomia dos estudantes como cidadãos conscientes após a escola, pois através das atividades de construção do conhecimento eles se tornam sujeitos ativos.

Nesse contexto, a pesquisa é uma importante aliada nos processos de ensinoaprendizagem no contexto escolar, pois aproxima os estudantes de forma ativa da construção do conhecimento, promovendo o embate entre suas representações, uma coleta de dados e as teorias científicas, contribuindo com reflexões sobre os problemas encontrados no cotidiano. Nesta lógica de ensino-aprendizagem, como afirma Libâneo (2011, p. 30): "O ensino exclusivamente verbalista, a mera transmissão de informações, a aprendizagem entendida somente como acumulação de conhecimentos, não subsistem mais".

\section{Estudo do meio como proposta de educação ambiental}

Como proposta de prática pedagógica socioconstrutivista para a Educação ambiental, temos o estudo do meio. Esta prática pedagógica tem como premissa a interdisciplinaridade na busca de desvendar a complexidade do espaço vivido. Nas palavras de Pontuschka; Paganelli e Cacete (2009, p. 173): “O estudo do meio, além de ser interdisciplinar, permite que aluno e professor se embrenhem num processo de pesquisa". Assim, para as autoras, o processo de pesquisa como uma forma ativa da relação ensinoaprendizagem, promove a possibilidade da descoberta diante de um meio qualquer, aguçando a reflexão do estudante para construção do conhecimento.

No caminho da educação ambiental, a proposta de estudo do meio realiza um movimento de apreensão do meio social, físico e biológico numa perspectiva interdisciplinar. De acordo com Pontuschka; Paganelli e Cacete (2009), para a concretização do estudo do meio, além da articulação entre os professores de diferentes componentes curriculares, existem algumas etapas preliminares. Ao primeiro momento, se faz necessário um encontro entre os sujeitos do conhecimento, professores e estudantes, 
através da mobilização da escola. Nesse encontro, de forma dialógica, os professores levantam as representações dos estudantes sobre o meio, geralmente o bairro da escola, perscrutando a problemática ambiental a ser estudada. Após essa etapa, se faz necessário uma visita preliminar ao meio, saindo da sala de aula. Após a visita preliminar, os sujeitos do conhecimento realizam o planejamento da atividade.

O estudo do meio é uma metodologia de ensino-aprendizagem inovadora, que busca um trabalho coletivo entre professores, estudantes, direção da escola e comunidade. Nesse sentido, o estudo do meio tem como premissa uma reconstrução do currículo escolar buscando contextualizar os conteúdos da problemática ambiental com a realidade vivida no bairro, abrindo espaço para a interdisciplinaridade. Buscando o entendimento do impacto da ação humana na dinâmica natural através de atividades econômicas e políticas, existem muitas possibilidades de estudo como a poluição da Bacia hidrográfica e do lençol freático; questão do lixo; a problemática das ilhas de calor com o adensamento urbano; desmatamento e a necessidade de conservação e/ou preservação da Mata Ciliar; a questão da moradia em vertentes e o problema do deslizamento; a questão agrária, do agronegócio; superexploração dos solos e sua degradação.

Como uma metodologia ativa no qual interagem a pesquisa e o ensino, uma das atividades fundamentais do estudo do meio é o trabalho de campo, que precisa ser meticulosamente planejado em sala de aula considerando as experiências vividas dos estudantes e suas representações. Em conjunto com as teorias e as representações dos estudantes sobre o meio, busca-se construir a pesquisa através de documentos, entrevistas, fotografias, vídeos, anotações e etc.

No interior do planejamento da atividade de campo, os professores orientam os estudantes na construção de um caderno de campo que busque potencializar a coleta de informações. O trabalho de campo deve ser tratado como revelador das contradições, um momento de diálogo entre os saberes proporcionando a reconstituição da memória dos moradores mais antigos e dos movimentos sociais. As entrevistas com os moradores associadas as representações vividas dos estudantes permitem um número cada vez maior de correlações. Para Pontuschka; Paganelli e Cacete (2009, p. 178): "Quando grupos de alunos, coordenados por professores, realizam uma pesquisa de campo no local em que vivem [...] passam a reconhecer e valorizar o patrimônio cultural de seu lugar. [...]”. Essa aproximação é muito positiva pois gera um maior interesse no entendimento dos processos.

Para as autoras, no tocante a entrevista, o importante é viabilizar a emersão da visão de mundo que o entrevistado apresenta, contribuindo com uma reconstituição da 
relação sociedade e natureza no bairro. Para tanto, quanto mais documentos públicos, cartogramas, fotos e vídeos os estudantes conseguirem levantar em suas pesquisas, mais fidedigno esse processo vai se revelar. A busca pelo entendimento dos impactos ambientais no interior do estudo do meio passa pela mediação do professor, contribuindo com os estudantes ao longo dos processos de ensino-aprendizagem. Após a realização das entrevistas, inicia-se o processo de transcrição das entrevistas e análise de conteúdo, constituindo uma fonte de referência para o entendimento do meio.

Com o material de pesquisa coletado, tem-se um retorno a sala de aula, em que os múltiplos saberes conquistados pelos estudantes no campo retornam para a construção do conhecimento. Nesse retorno, ocorre a socialização da pesquisa, em que o professor e os estudantes refletem coletivamente sobre o que revelam os registros, surgindo questões acerca dos eixos temáticos da educação ambiental que afloraram na pesquisa, em que os professores contribuem com a sistematização do material coletado, relacionando os conteúdos científicos e as descobertas. No interior de todo o processo de estudo do meio, tem-se uma didática diferenciada que propicia a aprendizagem e a internalização do conhecimento a partir da participação ativa do estudante em conjunto com o professor, outro sujeito no processo.

No âmbito do estudo do meio, o processo de criação e construção do conhecimento é constante, finalizando com a etapa final de exposição do conhecimento adquirido. Aí temos o processo de materialização do conhecimento com a escrita, a fala ou um objeto artístico, proporcionando a externalização do conhecimento. Nesse momento, surgem questões do que criar, um seminário, um jornal, um painel, um site, uma peça de teatro. Tendo como norte a construção de recursos didáticos através de materiais recicláveis, surgem inúmeras possibilidades de trabalho pedagógico. Aqui propomos a construção de Fantoches para a realização de teatros de bonecos, mediados por temas e conteúdos associados ao estudo do meio que os próprios estudantes pesquisaram.

Para Vigotsky (2014), a criatividade teatral na idade escolar relaciona de modo imediato eficaz e direto a criação artística com as experiências vividas. Em nosso caso, propomos a exposição teatral do conhecimento adquirido através do estudo do meio. De acordo com Vigotsky (2014), a representação teatral tem enorme valor na construção do conhecimento, tendo em vista que os próprios estudantes preparam a peça. Como ele destaca, a lei básica da criatividade na idade escolar é que o seu valor não reside no produto da criação, mas no próprio processo. Destarte, destacamos que a exposição teatral 
proporciona o exercício da imaginação criativa objetiva dos estudantes, tendo em vista que propomos o trabalho de exposição dos dados da pesquisa.

Nesse caso, temos uma possibilidade muito interessante para o retorno à comunidade, com a exposição dos resultados do estudo do meio através do teatro de fantoches, possibilitando um fortalecimento da identidade com o meio. Em termos práticos, a produção dos fantoches é realizada com materiais recicláveis, tornando-se pertinente pelo custo acessível e pela utilização de utensílios ecológicos. Para tanto, utilizamos uma garrafa pet de $250 \mathrm{ml}$ que servirá como cabeça do boneco; barbante para os cabelos; tecido para o corpo; papelão para as mãos; jornal para cobrir a garrafa e as mãos; cola e pincel. Com a cabeça e as mãos do fantoche cobertas com jornal, temos uma base para pintura do fantoche através da tinta PVA para artesanato. Com o jornal também se faz a boca e os olhos. Ver exemplo de fantoches nas figuras 1 e 2, que foram retiradas de uma prática pedagógica ${ }^{4}$ mediada pelo autor.

Figura 1: Teatro de Fantoches - Baixio das Palmeiras-CRATO/CE, 08/06/2013



FONTE: elaboração própria
Figura 2: Exemplo Fantoche - Baixio das Palmeiras-CRATO/CE, 08/06/2013



FONTE: elaboração própria

Sobre a construção dos bonecos, podemos dividir em cinco etapas: a primeira consiste em cortar e montar as bases das mãos com papelão e dos olhos e boca com jornal. Nessa etapa também se faz o encaixe para quem vai manusear os fantoches, com papelão em forma de cone na parte interna, colando nas mãos do boneco; a segunda fase se refere à colagem do jornal, fazendo uma cobertura da garrafa pet e das mãos, para que se crie uma base, a mais homogênea possível, o que facilitará a pintura dos bonecos, já na terceira etapa; quando a tinta secar se iniciará o quarto momento que é o da montagem das roupas.

\footnotetext{
${ }^{4}$ No âmbito das atividades da disciplina 'Linguagens e Metodologias no Ensino de Geografia' como professor substituto na Universidade Regional do Cariri - URCA.
} 
Necessita-se que o tecido das roupas tenha dimensão suficiente para cobrir a mão da pessoa que irá manusear o fantoche; a quinta e última etapa é colar o cabelo do boneco com lã. Os bonecos não possuem um padrão, podem ter as dimensões e feições que os estudantes quiserem criar conforme a mensagem a ser passada.

No interior desse processo, a aprendizagem dos estudantes ganha um corpo diferenciado, pois faz sentido para suas vidas. Através da atividade de pesquisa proporcionada pelo estudo do meio, os estudantes reconstroem o conhecimento em seu imaginário com base na fricção entre os conhecimentos empíricos e cotidianos com os conhecimentos científicos. Nesse embate, ocorre o processo de internalização do conhecimento, no qual os estudantes trabalham para expor com suas próprias palavras e exemplos os resultados do estudo do meio, através da atividade do teatro de fantoches que será exibida na própria comunidade pesquisada. De acordo com Carvalho (2012), a internalização do conhecimento implica desenvolver capacidades e sensibilidades para identificar e compreender os problemas ambientais e mobilizar-se enquanto um sujeito ecológico.

Assim, faz-se fundamental diferenciar um processo de educação que se orienta para a mudança dos comportamentos dos estudantes de um processo educacional que busca uma mudança das atitudes sobre o mundo através de uma formação humana. Para Carvalho (2012), uma educação comportamental se dá por satisfeita com a mudança de comportamento dos estudantes no interior da sala de aula com vistas a obter uma gratificação, muitas vezes uma nota ou aprovação. A autora argumenta que a mudança de comportamento não indica a presença de uma crença internalizada e consolidada, e se questiona: por que o aprendizado realizado na escola muitas vezes não se generaliza numa mudança de atitude nas ações da vida cotidiana dos estudantes?

A resposta para o questionamento está no fato de que o processo pedagógico tradicional não busca uma educação que faça sentido para a vida do estudante, se prendendo, em muitos casos, apenas numa educação verbal em que o estudante busca memorizar os conteúdos apresentados para utilizar na hora da prova. Por outro lado, o grande desafio da educação ambiental crítica é: “[...] ir além da aprendizagem comportamental, engajando-se na construção de uma cultura cidadã e na formação de atitudes ecológicas." (CARVALHO, 2012, p. 183). Tal processo formativo pressupõe a busca por um sentido de responsabilidade ética e social, considerando a importância de valores humanos de solidariedade e justiça ambiental. Nas palavras da autora: 
$\mathrm{Na}$ perspectiva de uma aprendizagem significativa, a intencionalidade pedagógica está na construção de novos sentidos e nexos para a vida, em que atividades, experiências, modos de fazer e informações estejam a serviço de um processo de formação de atitudes e não sejam um fim em si mesmos. Como sabemos, a internalização de um ideário ecológico emancipador não se dá apenas por um convencimento racional sobre a urgência da crise ambiental. (CARVALHO, 2012, p. 188).

Por fim, a atividade de exposição dos conhecimentos adquiridos no âmbito do estudo do meio permite a verificação dos processos de aprendizagem, em que o professor pode avaliar se realmente ocorreu uma internalização e apropriação do conhecimento. Este é o momento de um retorno à prática social, só que não apenas como representação, mas como sujeito social consciente em luta pela cidadania. O processo de avaliação se realiza na exposição teatral organizada pelos estudantes, mas o objetivo final da educação ambiental crítica é tocar emocionalmente os estudantes com um conhecimento que faça sentido para sua vida, com vistas a contribuir com um posicionamento perante o conteúdo que foi adquirido.

\section{Considerações finais}

Neste artigo, lembramos a importância do diálogo interdisciplinar para construção de uma educação ambiental crítica na educação básica, levando em conta que o mundo contemporâneo é permeado por inúmeras contradições e conflitos que se apresentam na realidade vivida dos estudantes, consubstanciando temas sensíveis para o ensino escolar. Como se sabe, a mundialização do capital, a urbanização desenfreada e a expansão dos circuitos de produção, circulação e consumo de mercadorias vem promovendo uma crise limite da relação entre sociedade e natureza. Como argumentamos, para o capitalismo sobreviver enquanto modo de produção, com seus altos índices de produtividade, precisa transformar a natureza em valor de troca. Toda essa complexidade vem exigindo o debate entre as diferentes disciplinas na busca da superação de uma visão unidimensional.

Em nossa proposta, destacamos a importância de que o conhecimento ambiental seja reconstruído no plano interno do imaginário dos estudantes para se tornar ação. Nessa perspectiva, o conceito de zona de desenvolvimento imediato é fundamental pois propõe uma articulação entre os conhecimentos prévios do cotidiano dos estudantes com os conhecimentos científicos. O levantamento teórico forneceu elementos para o entendimento dialético do processo educativo, em que os estudantes e professores são reconhecidos como sujeitos ativos em uma relação de interação. A metodologia do estudo 
do meio contribui de forma seminal para que os estudantes saiam do lugar comum da passividade no caminho da construção do conhecimento através da pesquisa. Ao final do processo de ensino-aprendizagem, os estudantes, como leitores do mundo, podem retornar para a sociedade como sujeitos ecológicos conscientes da crise ambiental.

Nesta lógica, no interior do processo de internalização do conhecimento ambiental, ocorre o envolvimento ativo dos estudantes com a problemática vivida no bairro, em que o ato educativo passa a ser compreendido em um sentido cultural que faz sentido ao universo simbólico dos estudantes. Ademais, a proposta do teatro de fantoches como materialização dos conhecimentos adquiridos no estudo do meio proporciona que os estudantes se expressem com suas próprias palavras, retornando para a comunidade de forma criativa para apresentar os resultados da pesquisa. Desta feita, consideramos que é essencial a renovação das práticas pedagógicas tradicionais, buscando superar uma educação desvinculada da vida dos estudantes com a premissa da formação humana para intervenção na vida social como sujeitos ativos.

\section{Referências}

CARVALHO, Isabel Cristina de Moura. Educação ambiental: a formação do sujeito ecológico. São Paulo: Cortez, 2011.

CASTORINA, Antônio. Piaget e Vigotsky: novos argumentos para uma controvérsia. Cadernos de Pesquisa. N. 105, 1998.

CHESNAIS, François. A mundialização do capital. São Paulo: Xamã, 1996.

HOBSBAWM, Eric. A era dos extremos: o breve século XX -1914-1991. SP. Ed. Companhia das letras, 2015.

KOSIK, Karel. Dialética do concreto. Rio de Janeiro, Paz e Terra, 1976.

LIBÂNEO, José Carlos. Adeus professor, adeus professor?: novas exigências educacionais e profissão docente. São Paulo: Cortez, 2011.

MARX, Karl. Teses a Feuerbach. In: MARX, Karl. A ideologia alemã. São Paulo: Boitempo, 2007.

MORAES, Antonio Carlos Robert. Meio Ambiente e Ciências Humanas. 4. edição - São Paulo: Annablume, 2005.

PONTUSCHKA, Nídia; PAGANELli, Tomoko; CACETE, Núria. Para ensinar e aprender geografia. São Paulo: Cortez, 2009. 
RODRIGUES, Arlete Moyses. Produção e consumo do e no espaço: problemática ambiental urbana. São Paulo, Hucitec, 1998.

VIGOTSKY, Lev S. A construção do pensamento e da linguagem. Tradução Paulo Bezerra. - São Paulo: Martins Fontes, 2001.

VIGOTSKY, Lev S. Imaginação e criatividade na infância. São Paulo: Martins Fontes, 2014.

Submetido em: 19-06-2020.

Publicado em: 18-12-2020. 